\section{Do diseases really exist?}

\author{
John Launer
}

Is there such a thing as a disease? For most doctors, the question may seem absurd, and barely worth a moment's thought. Yet the question is a legitimate one, and is taken seriously by a range of people from biologists to philosophers. There are many reasons why. For example, as any doctor will recognise, the definitions of many diseases are quite arbitrary. They vary from one place to another, and from one year to the next. Conditions like hypertension and hyperlidaemia occur along a continuum and have to be defined by committees. In the same way, there is no clear line between glucose intolerance and diabetes. The definitions of diseases like asthma and bronchitis change with a fair degree of frequency, as do the classifications of other kinds of problem like some renal and rheumatic diseases. Fashion, politics and profit all play a part in this process, leading to over-medicalization in many instances. ${ }^{1}$ Thus, the very best that can be said for many of the diseases we treat are that they are shifting concepts and have fuzzy boundaries.

The boundaries of disease are arbitrary in another way too. We are often at a loss to explain why an apparent disease has such diverse effects. One person may have significant arthritic changes on an X-ray but little pain and full mobility, while another with lesser apparent joint damage is in agony and housebound. In the same way, one individual may live cheerfully with extensive vitiligo, while another shuns social contact because of one minor patch of depigmentation. To lump any such problem together under a single diagnosis is to ignore a whole range of dimensions including function, attitude and subjective experience, in favour of what the doctor can merely see or investigate. Diseases, in other words, are often just convenient generalisations.

Looked at historically, the concept of disease may be even more questionable. Some diseases like neurasthenia have vanished without trace, while others like chronic fatigue syndrome and fibromyalgia have arisen to take their place. Psychiatric conditions are particularly subject to

Correspondence to Dr John Launer, Faculty Development, Health Education North West London, Stewart House, 32 Russell Square, London WC1B 5DN, UK: john.launer@londondeanery.nhs.uk upheavals of this kind. It would be nice to think that these changes are always due to increased scientific knowledge, but they also reflect ideological positions - for example, different ways of conceptualising the relationship between the mind and the body. Over longer periods of time, whole systems of belief about disease are prone to shift, so that the descriptions of signs, symptoms and diagnosis offered by one generation of physicians may be literally incomprehensible to the next. This is just as true for physical problems as it is for mental ones. As many people have argued, diseases are socially constructed. ${ }^{2}$

From an evolutionary point of view, the notion of diseases is contestable as well. Some evolved conditions may be deleterious to humans in certain ways but advantageous in others. The increased resistance of sickle cell carriers to malaria is one wellknown example. It is probably best to regard the whole field of microbiology in ecological terms, seeing primitive organisms and higher ones like human beings involved in a continual process of interaction, including both competition and collaboration. ${ }^{3} \mathrm{~A}$ similar framework can be used for thinking about our genes, which promote our wellbeing until they have given us a fair chance of perpetuating our genetic line, but then progressively work against our interests as individuals through malignancy, autoimmunity or degeneration. Here too, the concept of disease is probably less cogent than of an internal ecosystem. ${ }^{4}$

\section{ILLUSORY CONCEPT}

In an influential essay with the title 'Do we need the concept of disease?' the Swedish philosopher Germund Hesslow argues that the whole notion of disease is illusory and largely irrelevant to the practice of medicine. ${ }^{5}$ His case is based on the observation that what patients and doctors generally have to address is a wish to change or improve matters in one way or another, but this desire often maps poorly onto any idea of health or disease. He begins with a parable about a man who is upset because his car will not accelerate as fast as the same model owned by a friend, and who gets drawn into a fruitless argument with a mechanic who says he cannot find anything wrong with the engine. As Hesslow points out, what the customer is seeking is not a discussion about the meaning of words like 'faulty' but a practical adjustment that will allow the car to do what he wants. Hesslow cites several states that are normally classified as diseases but not treated - like small birth marks or benign tumours - and some pathological conditions such as sterility that may be induced intentionally. He points to the way that doctors carry out cosmetic surgery or gender reassignment, without having to declare that having a large nose or being male are diseases. Like many other thinkers, he rejects the naïve idea that disease is a deviation from some ideal 'design', but suggests that the concept needs to be abandoned rather than being replaced by another one.

Hesslow recognises that there are some circumstances, such as claims for medical insurance and disability rights, where external agencies have to ask doctors for information about patients in order to decide how to allocate resources. However, he argues that the distinction between health and disease is irrelevant in these circumstances too. What matters in practice, he proposes, is how clearly the agencies draw up the rules to guide these decisions, and how consistently they apply them: for example, in determining the level of discomfort, pain or anxiety suffered by the individual, or in predicting the likely level of future disability. Hesslow also examines the issue of legal responsibility when a crime is committed by someone with a mental illness. Here too, he suggests that the question of disease is immaterial. Instead, the crucial consideration is whether psychiatrists believe that the wrongdoers can understand the consequences of their actions, or be influenced by punishment.

The paper concludes as follows:

'Young medical students who begin their studies with the idea that diseases are unpleasant abnormal conditions which should be treated and which entitle the patient to medical insurance are not completely wrong. Statistically speaking, they will certainly more often be right than wrong, but, as we have seen, there are many exceptions to these rules which the students will gradually learn to recognise as they mature. However, maturation does not consist in their acquiring a more sophisticated view of health and disease, but in their replacing "health" and "disease" with other concepts, better suited to their purpose.'

If Hesslow is right, perhaps the concept of 'disease' is one that doctors need to learn in the earlier stages of training, but should forget afterwards. 


\section{Competing interests None.}

Provenance and peer review Commissioned; internally peer reviewed.

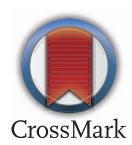

To cite Launer J. Postgrad Med J 2014;90:425-426.

Postgrad Med J 2014;90:425-426.

doi:10.1136/postgradmedj-2014-132818

\section{REFERENCES}

1 I Heath. When overdiagnosis meets vested interest. BMJ 2013;347:f6361.
2 Conrad P, Barker K. The social construction of illness: key insights and policy implications. J Health Soc Behavior 2010;51:S67-S79.

3 Ulvestad E. Co-operation and conflict in host-microbe relations. APMIS 2009;117:311-22.

4 Mauricio R. Can ecology help genomics: the genome as ecosystem? Genetica 2005;123:205-209.

5 Hesslow G. Do we need a concept of disease? Theoretical Med 1993;14:1-14. 